\title{
Assessment of energy system management - the case study of Kazakhstan
}

\author{
Galimkair Mutanov ${ }^{1, *}$, and Sayabek Ziyadin ${ }^{1}$ \\ ${ }^{1}$ Al-Farabi Kazakh National University, 050040, Almaty, Kazakhstan
}

\begin{abstract}
The article discusses the relevance of the problem of energy efficiency of industrial enterprises, along with increasing environmental safety of production and increasing social responsibility. The technique of estimation of production efficiency and its influence in management of ecological system on the basis of energy-entropy method is considered. Relevant questions are: improvement of the universal principles of energy efficiency in specific sectors and to develop tools of economic analysis energy infrastructure of industrial enterprises on the basis of the energyentropy method using various ratios and find new ways of efficient use of energy. The purpose of this article is to develop new methods for assessing the efficiency of production and management. The problem is largely actualized by the fact that at present the question of assessing the effectiveness of energy systems management.
\end{abstract}

\section{Introduction}

The problems of energy efficiency, along with the improvement of environmental safety of production and the enhancement of social responsibility, become the central object of research of modern theory and practice of industrial enterprise management.

From an energy and climate policy point of view, improving energy efficiency has a wide positive effect. Energy efficiency contributes to reducing greenhouse gas (GHG) emissions by helping countries meet climate change targets, gain economic benefits, reduce electricity bills and homeowners, and create new jobs in environmentally friendly technologies and services. For example, according to the estimates of the European Climate Change Program, the Building Energy Performance Directive (2001/91/EC) will reduce emissions by 220 megaton $\mathrm{CO}_{2}$ equivalent, including 35-45 megatons by 2010 , and the bulk of this reduction will be achieved at negative costs (i.e. can be financed by reducing costs). The main components of such programs are thermal insulation (walls, roofs and floors) and efficient heating systems [1]. Jansen, \& Bakker (2009) note, those improvements such as thermal insulation and building automation can be very economical for end users (with the right price signals) and create advantages in terms of employment, energy security and air quality, as well as reducing GHG emissions. [2]

A radical solution to the problem lies in the transition from extensive to intensive production methods using fundamentally new organizational and technical solutions and

* Corresponding author: angela-1309.m@yandex.ru 
the introduction of new environmentally friendly, resource-saving technologies. Such an approach will ensure a drastic reduction in the energy and material consumption of domestic products and the anthropogenic impact on the environment. In addition, the provision of improved energy efficiency stimulates the introduction of new innovative technologies and solutions, which in turn stimulates the active interaction of the development of science and the commercialization of $R \& D$, which involves the economically effective (with profit for the developer and the recipient) implementation of technologies on an industrial scale as noted in the research work of Ziyadin, Omarova, Doszhan, Saparova, \& Zharaskyzy (2018). [3]

Increasing the relevance of energy conservation and the use of alternative energy sources in connection with global and local resource crises led to the formation of a developed system of international standardization in the field of energy management, which aims to regulate and disclose the content of principles for building energy efficient business processes and developing rational energy management policies of enterprises.

The issues of improving the universal principles of energy efficiency within individual industries and the development of tools for the economic analysis of the energy infrastructure of industrial enterprises based on the energy-entropy method using various kinds of coefficients and finding new ways to efficiently use energy remain relevant.

The purpose of this study is to develop new energy-entropy methods for assessing the efficiency of production and management. The problem is largely actualized by the fact that now the issue of assessing the effectiveness of environmental systems management, based on the energy-entropy method, remains poorly understood.

\section{Theoretical framework}

An important indicator that characterizes the level of socio-economic development of society is the efficiency of the use of material and energy resources per unit of gross national product produced.

Due to the limitations of its own material and raw material base and the high energy intensity of production, the efficient use of energy resources is one of the most important national tasks, the solution of which is inextricably linked with the further socio-economic development of the country and the strengthening of energy independence and security. High prices for fuel and energy resources have an impact on industrial production, since in the structure of gross domestic product, more than $31 \%$ is accounted for industrial products and a significant share of fuel and energy resources is consumed. This makes it necessary to search, develop and implement measures aimed at the efficient use of energy resources in this sector of the national economy, which can be achieved by introducing energy-saving technologies and measures of an organizational and economic nature.

As part of ensuring sustainable and innovative development of industrial enterprises, this problem is reflected in the research work of many scientists. For example, Ziyadin and Yessenova (2015) consider the diversification of industrial enterprises in the region as a method of increasing the efficiency of industrial enterprises.[4]

There are many definitions of the concept of "energy efficiency". According to Pospelova (2000), "energy efficiency is a characteristic of the socio-economic, technical system, technological process, production equipment, household appliances, etc., suggesting their maximum use of exergy (ability to perform work) of energy resources. Energy efficiency is the result of the energy saving process"[5].

According to Padalko and Khaustovich (2006), "energy efficiency is a concept that characterizes the degree of beneficial use of the primary energy supplied to a particular power installation and depending on the technology used for production, performance of works and provision of services. For industrial enterprises, an indicator of the energy 
efficiency of their operation is the indicator of specific energy consumption for their products, or the indicator of energy intensity. It shows how much energy or energy is spent on the production unit of an enterprise" [6].

Ganzha (1998) noted that "the inverse of energy intensity is called energy efficiency. Energy efficiency characterizes the quantity of products in terms of value that can be produced at the cost of a unit of fuel and energy resources [7].

The EU Energy Efficiency Directive uses a very broad definition: "energy efficiency" means the ratio of output of performance, service, goods or energy, to input of energy [8].

It is observed that there is a lot of research on the optimization of the activities of oil and gas enterprises and the efficiency of their energy consumption. For example, to optimize the investment portfolio of oil and gas enterprises, Mutanov, Milosz, and Kozhanova (2018) offered simulating modeling [9]. Mousavi-Avval, Rafiee, Jafari, \& Mohammadi (2011) investigates three approaches to saving energy in future wireless networks. These include sleep mode techniques to switch off radio transmissions whenever possible; femtocell and relay deployments; and multiple antenna wireless systems [10]. Subramanyam, Paramshivan, Kumar, \& Mondal (2015) developed Sankey diagrams that map energy flow for both the demand and supply sides for the province of Alberta, Canada [11]. In the researches of Mutanov, Milosz, Saxenbayeva, Kozhanova (2018), a dynamic model was built to analyze the forecasting of the scale and structure of investments for the oil industry. It also describes the problem of extracting data in intelligent information systems[12]. The formulated model can be used to analyze and predict the structure and size of the investment process as a new method and provide a basis for decision-making. Sozer (2010) offers improving energy efficiency through the design of the building envelope [13].

Despite the significant number of publications related to reducing energy intensity, a number of problems related to the efficient use of energy resources in industry remain insufficiently studied; there is no single approach to the definition of energy efficiency. In the economic literature, the composition and methods of influence of factors on the reduction of energy consumption are insufficiently studied; there is no mechanism for managing energy consumption in industry, as well as an integrated approach to material incentives that ensures the most economical use of energy resources in enterprises.

\section{Methodology}

\subsection{Analysis of energy consumption in Kazakhstan}

On the world stage, the role of Kazakhstan as a producer of energy resources is especially noticeable. In terms of proven reserves of oil, coal and uranium, Kazakhstan is in the top ten countries, and in terms of natural gas reserves - in the first 20 countries in the world. In addition, Kazakhstan is the world leader in uranium mining, and is among the top ten countries in the world in coal production and in the top twenty in oil production annually. Over the past two decades, the country has almost quadrupled its oil production and is playing the role of a new global "heavyweight" in this category. It is expected that over the next two decades, the largest increase in oil production among the countries of the Commonwealth of Independent States (CIS) will be observed in Kazakhstan.

Kazakhstan has significant reserves of coal, uranium, oil, and natural gas, while the country has the potential in hydropower and in the use of other renewable energy sources. The total amount of recoverable fuel resources (oil, gas, coal and uranium) in Kazakhstan is about 34.9 billion tons of oil equivalent (see Fig. 1). [14] 


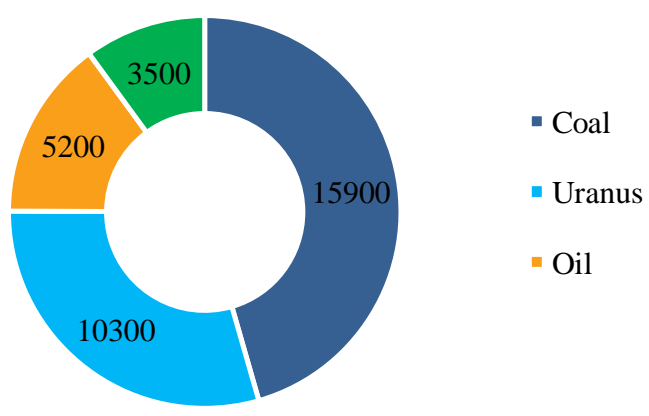

Fig. 1. Proved energy reserves of the Republic of Kazakhstan, billion tons of oil equivalent (modified from KAZENERGY, 2017).

In the structure of recoverable natural energy resources of Kazakhstan, the main share is made up of coal and uranium reserves (46\% and 30\%, respectively), while oil and gas account for not more than $25 \%$.

Kazakhstan has vast reserves of natural and energy resources. Despite this, the generated fuel and energy balance for 2017 showed that the republic does not fully meet domestic energy demand, where imports account for 3\% of total resources. Compared to the level for 2016, the extraction (production) of fuel and energy resources in 2017 increased by $4.8 \%$, the share of which in the resource part was $74.8 \%$ (Fig. 2).

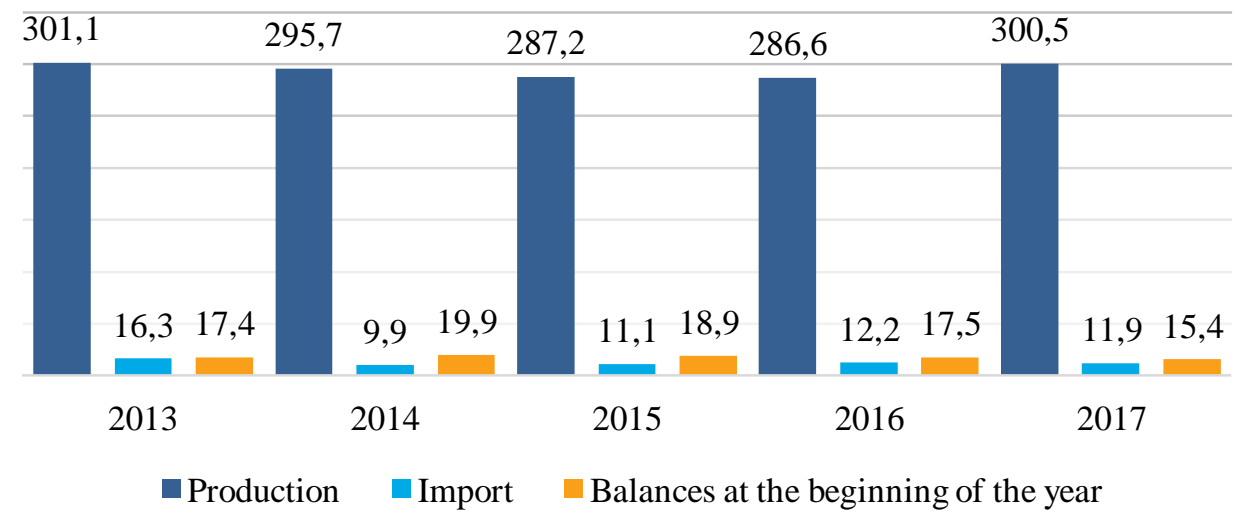

Fig. 2. The structure of the formation of the resource of fuel and energy resources (modified from Committee on Statistics of the Ministry of National Economy of the Republic of Kazakhstan, 2018) [15]

Changes also occurred in the structure of the distribution part: the proportion of the volume of fuel and energy resources supplied to the domestic market of the republic increased from $51.1 \%$ in 2013 to $58.9 \%$ in 2017 and the share of exports of fuel and energy resources decreased from $40.3 \%$ to $36.2 \%$, respectively (Fig. 3 ). 


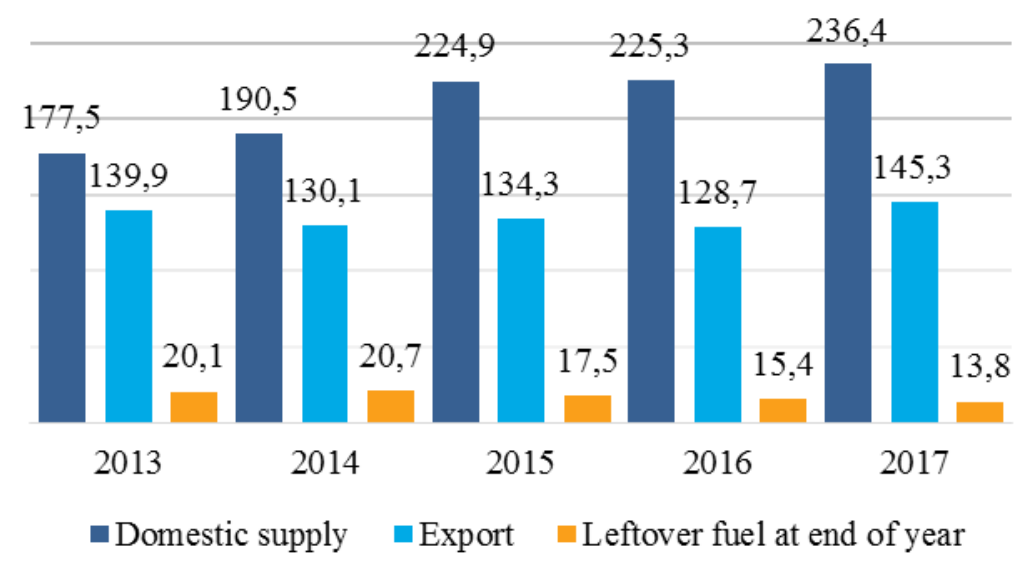

Fig. 3. The structure of the distribution of fuel and energy resources (modified from Committee on Statistics of the Ministry of National Economy of the Republic of Kazakhstan, 2018)

In 2017 in the domestic market of the republic, 236.4 million tons of oil equivalent were consumed here or $58.9 \%$ of the total amount of fuel and energy resources, of which $20.4 \%$ was spent on conversion to other types of energy and $43.7 \%$ was spent on production and technological and other needs.

One of the main reasons for the significant discrepancies between Kazakhstan and international estimates of mineral reserves is the use of various techniques. In Kazakhstan and in a number of other CIS countries, the Soviet system of classification of reserves and resources is used, based on the category approach determining the balance, balance and potential reserves. The classification of reserves and resources used by other countries is based on a probabilistic approach to the accuracy of calculating reserves and resources and takes into account economic and technical factors affecting production.

By the level of consumption of primary energy resources, according to the data of the International Energy Agency (IEA) (2018) and the World Bank (Banerjee et al., 2018), Kazakhstan is on the 28th place in the world with a consumption volume of 37.655 Mtoe as of 2016, which corresponds to $0.39 \%$ of the global consumption of primary energy resources (Fig. 4). [16] 


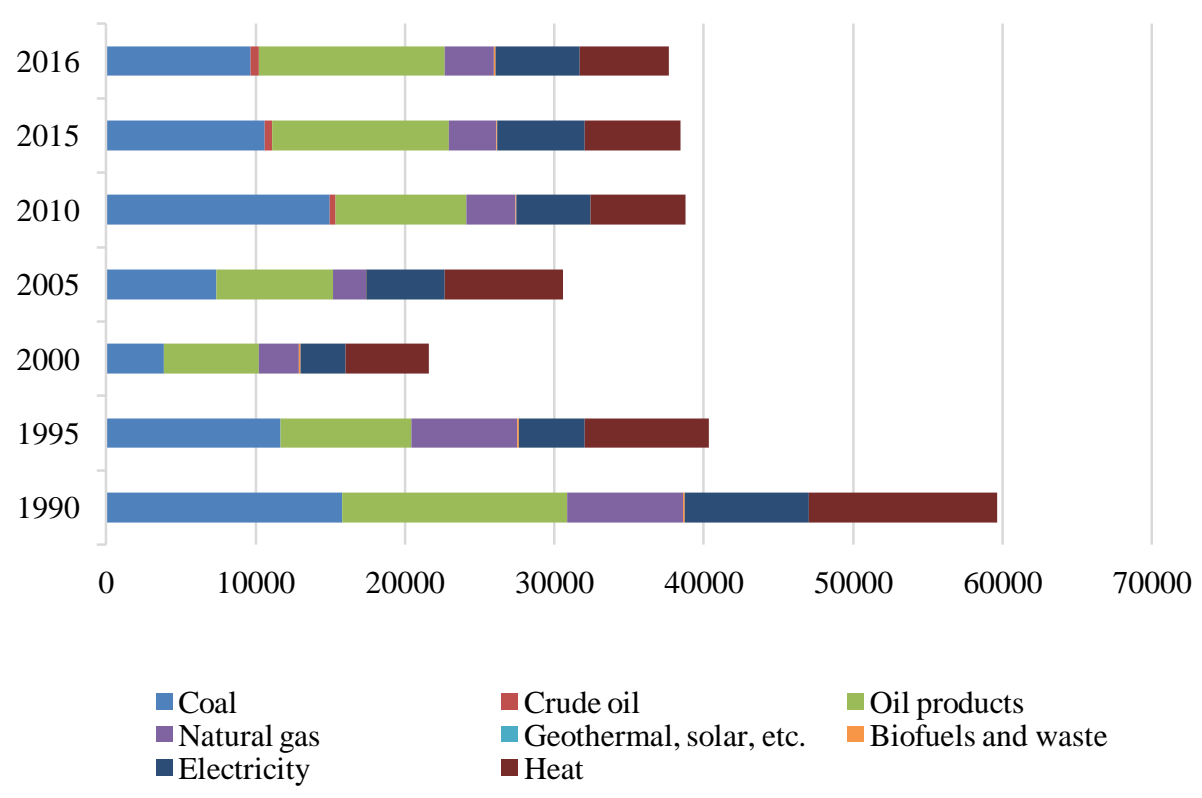

Fig. 4. Total Final Consumption (TFC) by source Kazakhstan 1990-2016, ktoe (modified from IEA, 2018)

In 2016 , there is a decrease in the level of coal consumption by $8.6 \%$ compared with 2015. The growth rates of the share of oil and natural gas were more moderate. The share of electricity and heating in the final energy consumption remained at a constant level.

With the fall in oil prices over the past few years, Kazakhstan's economic growth has slowed. For the electricity sector of Kazakhstan, this new reality has had a significant impact on annual electricity consumption, which, since 2012, has varied in a relatively limited range of about 90 billion $\mathrm{kW} / \mathrm{h}$. In addition, despite the fact that electricity consumption in 2016 increased compared with a year earlier, it will grow at a much slower average annual rate than those observed during the last decade. Thus, at first glance, it seems that the economic situation (along with the recent expansion of the network and the increase in the available capacity of power plants) eliminated the need for the urgent addition of new generating capacity.

In recent years, special attention has been paid to the issues of energy efficiency and energy saving in the Republic of Kazakhstan. At present, a regulatory legal framework has been created in this area and government bodies of the Republic of Kazakhstan are actively working to create a full-fledged energy efficiency system taking into account measures to modernize industries, introduce a technical regulation mechanism and energy accounting of enterprises, improve the quality of management and skills of production personnel, and promote energy saving among the population and increasing the investment attractiveness of energy efficiency projects.

The urgency of improving energy efficiency and energy saving is confirmed by the content of the President of Kazakhstan Nursultan Nazarbayev's (2018) Address to the Nation of Kazakhstan dated October 5, 2018 "Growth of the welfare of Kazakhstanis: increase of incomes and quality of life» and the state program of industrial-innovative development of the Republic of Kazakhstan for 2010-2014 (Decree of the President of the Republic of Kazakhstan, 2010). As part of these documents, a number of tasks have been set, one of which is to reduce the energy intensity of the gross domestic product of the 
Republic of Kazakhstan by at least $10 \%$ by 2015 and by at least $25 \%$ by 2020 . Although the prospects for economic growth in Kazakhstan in the medium term remain favorable, the global financial and economic crisis has revealed a serious imbalance in the country's longterm economic development, in particular, its dependence on commodity exports. In a period when, under the influence of rising oil prices and production growth, investment of human and financial resources will be channeled into traditional energy, diversification of the economy is not an easy task. Carefully planned energy transformation is a fundamental development task for Kazakhstan. Domestic demand for energy, in particular for electricity, is growing in Kazakhstan. Instead of building new generating capacity and importing energy from other countries, the government of Kazakhstan is interested in both diversifying its energy base and reducing carbon dioxide emissions [17], [18].

The environmental policy, and in particular the policy related to climate change, serves as an additional lever for creating incentives for the transformation of Kazakhstan's energy sector. So far, as the Climate Laws, Institutions and Measures Index (CLIMI) shows, Kazakhstan faces serious challenges in both developing and implementing appropriate policies. Kazakhstan's CLIMI index is 0.226 , which means that it ranks 61 st in the world (the United Kingdom leads, with an index of 0.801) (OECD, 2012).

However, the scale of the tasks to be solved in the country is primarily indicated by energy efficiency and carbon efficiency of the economy.

\subsection{Evaluation of production efficiency by the criterion of energy saving based on the energy-entropy method}

The authors, based on the above studies of the formation and development of innovative activities of enterprises as a system and the laws of energy-entropy, reviewed the analyzed production, revealed the cyclical nature of innovative development and suggested using the energy-entropy balance approach to the management of innovative activities

An example of entropy calculation (quantitative influence of entropic processes on production) in the case of two irreversible processes:

(1) according to the linear law $f_{i}=\sum_{j=1, n} k_{i j} X_{i}, i=\overline{1, n}$, the flows are expressed as

$$
f_{1}=k_{11} X_{1}+k_{12} X_{2}, f_{2}=k_{21} X_{1}+k_{22} X_{2},
$$

where, $X_{1}, X_{2}$ are thermodynamic forces (disturbance); for the entropy source in $\sigma=\sum_{i} f_{i} X_{i}=\sum_{i, j} k_{i j} X_{i} X_{j}$ we get the square-law form

$$
\sigma=k_{11} X_{1}^{2}+\left(k_{11}+k_{22}\right) X_{1} X_{2}+k_{22} X_{2}^{2}
$$

According to $\sigma=\sum_{i} f_{i} X_{i}=\sum_{i, j} k_{i j} X_{i} X_{j}>0$, the square-law form must be positive for all values of $X_{1}$ and $X_{2}$ except for $X_{1}=X_{2}=0$ when the entropy production is equal to zero (but nothing changes in the system). According to this requirement gives the following inequalities:

$$
k_{11}>0, k_{22}>0,\left(k_{12}+k_{21}\right)^{2}>4 k_{11} k_{22} .
$$


Hence, coefficients k11, k22 are positive, whereas reciprocity coefficients $k_{12}, k_{21}$ can be both positive and negative but their values are limited by the condition (3).

For the general case, we will introduce the following notations:

$$
\begin{gathered}
k_{i j}=k_{(i j)}+k_{[i j]}, \\
k_{(i j)}=k_{(j i)}, \\
k_{[i j]}=k_{[j i \bar{L}} .
\end{gathered}
$$

Therefore $k_{(i j)}$ and $k_{[i j]}$ are symmetric and asymmetric parts of kinetic coefficients. According to Mutanov (2015), the asymmetric part does not contribute to the production of entropy $\sigma=\sum_{i} f_{i} X_{i}=\sum_{i, j} k_{i j} X_{i} X_{j}$ and, hence:

$$
\sigma=\sum_{i_{j} j} k_{(i j)} X_{i} X_{j} \geq 0
$$

or in matrix representation:

$$
\sigma=X^{T} * K * X \geq 0
$$

where, $X=\left(\frac{X_{1}}{X_{n}}\right), X^{T}=\left(X_{1}, \ldots, X_{n}\right)$ are the force vector and transposed force vector; $K=\left(k_{(i j)}\right)_{i, j=1, n}$ is a symmetric part of matrix $K$.

According to the theory of matrices of a special type, for any quadratic form there exists such a linear transformation, which transforms this quadratic form into a quadratic form in new variables with its subsequent transformation into a diagonal form. In particular, for the real symmetric matrix $K$ there is such a real nonsingular matrix $T$ that matrix $K=\bar{T}^{\bar{T}} * K * T$ is diagonal. The transformation to the main axes normalizes the given quadratic form:

$$
X^{T} K X=X^{T} \tilde{K} X=\sum_{i} \tilde{k}_{i i} \tilde{X}_{i}^{2}=\sum_{i} \lambda_{i} X_{i}^{2},
$$

where, $\lambda_{i}$ is the eigenvalue of matrix $K$ found as a solution to the characteristic equation

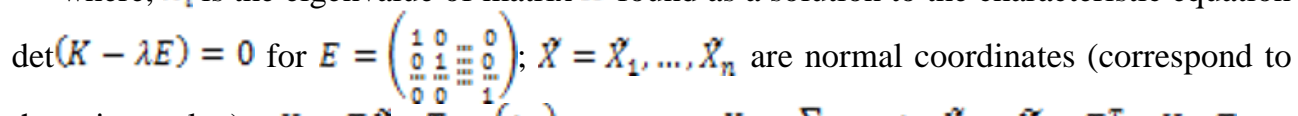
the eigenvalue); $X=T \hat{X}, \stackrel{T}{T}=\left(t_{i j}\right)_{i_{j} j=1, n}$ or $X_{i}=\sum_{k=1, n} t_{i k} \hat{X}_{k} ; \quad \tilde{K}=T^{T} * K * T$ or $\tilde{k}_{i k}=\sum_{j, h=1, n} k_{(j h)} t_{j i} t_{h k}$.

An additional transformation (normalization) $\hat{X}_{i}=Y_{i} /\left|\sqrt{\lambda_{i}}\right|, \quad i=\overline{1, n}$ transforms formula (7) to the canonical form:

$$
X^{T} K X=\Sigma_{i} \xi_{i} Y_{i}^{2},
$$

where coefficients

$$
\xi_{i}= \begin{cases}+1, & \text { if } \lambda_{i}>0 \\ -1, & \text { if } \lambda_{i}<0 \\ 0, & \text { if } \lambda_{i}=0\end{cases}
$$

For practical purposes, we recommend:

- $\quad$ an estimation relation 


$$
\left.\begin{array}{c}
C F=\lambda_{1} X_{1}^{2}+\lambda_{2} X_{2}^{2}+\cdots+\lambda_{n} X_{n}^{2} \\
\left.\lambda_{\min }=\min _{i=1, n}\left\{\lambda_{i}\right\}, \lambda_{\max }=\max _{i=1, n}\left\{\lambda_{i}\right\},\right\} \\
\leq \lambda_{\max }\left(X_{1}^{2}+\cdots+X_{n}^{2}\right)
\end{array}\right\} \Rightarrow \lambda_{\min }\left(X_{1}^{2}+\cdots+X_{n}^{2}\right) \leq K F
$$

or

$$
\lambda_{\min } \sum_{i} X_{i}^{2} \leq K F \leq \lambda_{\max } \sum_{i} X_{i}^{2} .
$$

Here $\sum_{i} X_{i}^{2}$ is the square of the length of the deviation vector $X^{2}:\|\hat{X}\|^{2}=\sum_{\mathrm{i}} \hat{X}_{\mathrm{i}}^{2}$. As the linear transformation does not distort the sizes, $\|X\|^{2}=\|X\|^{2}$ is valid, i.e., the estimation is correct:

$$
\lambda_{\min } \sum_{i} X_{i}^{2} \leq K F \leq \lambda_{\max } \sum_{i} X_{i}^{2}
$$

- for the comparative analysis the following fact is used: For any two real, symmetric forms $X^{T} M X$ and $X^{T} K X$ there is a real transformation such as $f_{i}=\sum_{j=1, n} k_{i j} X_{i}$, $i=\overline{1, n}$, or $F=K * X, \sigma=X^{T} * F=X^{T} * K * X$ simultaneously transforming the given forms to the canonical form.

The possibility to transform two quadratic forms to a canonical form enables comparison of two single-type manufacturing departments at different enterprises or to compare products of different technological levels produced at the same enterprise.

For non-closed systems the quadratic form is not necessarily positively defined. The comparative analysis is based on the following theorem: If at least one of the two real quadratic forms is positively defined, there is a basis in which both forms will get a canonical form. The results of the theorem can be applied to the matrices defined numerically. For example, for a closed system one can use the model (the standard) for comparison of results and conclusions of a real non-closed system. Comparing open systems with the standard, it is possible to rank them according to the production efficiency and operating quality [19].

\section{Conclusion}

Energy in the history of humankind has always formed the basis for economic growth, to which the requirement of advanced development was applied, in the form of not only extensive growth in the number and capacity of power plants and the capacity of the network infrastructure, but also the development of technology.

Currently, the world is undergoing a global energy transformation. The introduction of a complex of new solutions (starting with "green" energy and new generations of nuclear reactors and ending with intelligent automatic, so-called "smart" power grids and consumer services based on "Internet of Things" technologies [IoT]) leads to an increase in investment and costs for R\&D in the industry, growth of venture financing and other processes. The scale of the changes is so significant that at one time in the US and the EU, political leaders and part of the expert community even assumed that the development of new electric power industry technologies would help in overcoming the recession and in the transition to a new economic cycle.

Thus, all over the world, regulators and energy companies are faced with the difficult task of meeting growing demand as a condition for economic growth, social stability and profits, and / or reproduction of the electricity infrastructure. However, it is extremely inexpedient for all subjects to enter the new investment "super cycle" within the framework 
of the traditional model of the electric power industry due to its high cost, low efficiency and environmental friendliness, as well as a long deployment time.

The studies reviewed publications on the optimization of production activities, and reviewed the basic definitions of the concept of "energy efficiency". Based on the analysis, it was concluded that now the issue of assessing the effectiveness of environmental systems management, based on the energy-entropy method, remains poorly understood.

The main scientific findings are as follows:

1. Analysis of the main problems in Kazakhstan showed that the country's economy is characterized by low energy efficiency, and the current practice of assessing the economic efficiency of production does not use indicators that can evaluate energy efficiency not in terms of value, but in energy terms.

2. Based on the above, it can be concluded that the introduction of this method, aimed at evaluating energy efficiency, will allow in practice to realize low-waste energyefficient production, which will meet the promising requirements of environmental compatibility of industrial facilities with the environment.

\section{References}

1 OECD Promoting energy efficiency in the residential sector in Kazakhstan: Designing a public investment programme. OECD EAPTask Force, OECD, Paris. (2012)

2 J.C. Jansen, Energy services security: concepts and metrics. Petten: ECN. (2009)

3 S. Ziyadin, A. Omarova, R. Doszhan, G. Saparova, G. Zharaskyzy, Diversification of $R$ and $D$ results commercialization. Prob. and Perspect. in Manag., 16(4), 331-343 (2018)

4 S. Ziyadin, G. Yessenova, Prerequisites for development and diversification of production in industry. Ec. Annal.-XXI, (5-6), 37-40 (2015)

5 European Union Understanding energy efficiency. Eur. Parliam.Res. Serv., 10 (2015)

6 G. Mutanov, M. Milosz, A. Kozhanova, Systematically dynamic model-building approach of oil company. J. of Eng. and Appl. Scie., 13, Issue 10, pp. 33963401 (2018)

7 S.H. Mousavi-Avval, S. Rafiee, A. Jafari, A. Mohammadi, Improving energy use efficiency of canola production using data envelopment analysis. (DEA) approach. Energy, 36(5), 2765-2772 (2011)

8 V. Subramanyam, D. Paramshivan, A. Kumar, M.A.H. Mondal, Using Sankey diagrams to map energy flow from primary fuel to end use. Energ. Conv. and Manag., 91, 342-352 (2015)

9 G. Mutanov, M. Milosz, Z. Saxenbayeva, A. Kozhanova, Investments Decision Making on the Basis of System Dynamics. Stud. in Comput. Intell., 769, pp. 293-303 (2018)

$10 \mathrm{H}$. Sozer, Improving energy efficiency through the design of the building envelope. Build. and envir., 45(12), 2581-2593 (2010)

11 KAZENERGY National Energy Report 2017. Association of Kazakhstan organizations of oil and gas and energy complex "KAZENERGY”, 162 (2017) 
12 Committee on Statistics of the Ministry of National Economy of the Republic of Kazakhstan Fuel and energy balance of the Republic of Kazakhstan 2013-2017. Stat. compil., 43 (2018)

13 International energy agency World Energy Outlook 2018. IEA Public.Intern. Energ. Agency (2018)

14 State of the Nation Address by the President of the Republic of Kazakhstan Nursultan Nazarbayev New opportunities under the fourth industrial revolution (2018) http://www.akorda.kz/en/addresses/addresses_of_president/state-of-thenation-address-by-the-president-of-the-republic-of-kazakhstan-nursultannazarbayev-january-10-2018

15 Decree of the President of the Republic of Kazakhstan State program of industrial-innovative development of the Republic of Kazakhstan for 2010-2014 (2010) http://www.akorda.kz/upload/SPFIID.doc

16 G. Mutanov, Mathematical Methods and Models in Economic Planning. Manag. and Budget., p. 364, Springer Berlin Heidelberg (2015) 